\title{
ITED 3 - DIMENSIONAMENTO DAS REDES DE CABOS COAXIAIS
}

\section{Introdução}

Em Setembro de 2014 foi editada a 3a Edição do Manual das Infraestruturas de Telecomunicações em edifícios (ITED), que veio responder à necessidade de uma atualização técnica, bem como dar resposta à questão do paradigma do setor imobiliário.

Essa 3a Edição apresentou algumas alterações face à edição anterior, designadamente no que toca ao dimensionamento de redes de cabos coaxiais (CC).

Com este artigo, pretende-se apresentar as alterações mais significativas entre a 2a e $3^{\underline{a}}$ Edição do Manual ITED, nomeadamente no que toca ao dimensionamento de redes de cabos coaxiais.

Pretende-se, também, apresentar uma aplicação informática que foi desenvolvida no âmbito do curso da Licenciatura em Engenharia Eletrotécnica - Sistemas Elétricos de Energia, evidenciando os vários aspetos no domínio do dimensionamento de redes coaxiais em redes coletivas e individuais.

Por fim, apresenta-se um caso de estudo, que pretende ao mesmo tempo demonstrar a forma como a aplicação informática funciona, bem como a sua fiabilidade.

\section{3a Edição do Manual ITED}

Com o passar dos anos, as tecnologias de radiodifusão vão evoluindo, permitindo ir mais longe, no que toca à qualidade e quantidade de informação, bem como na fiabilidade e eficiência dos sistemas.

Com estas evoluções, os profissionais de telecomunicações, projetistas e instaladores, têm de se adaptar a estas novas realidades, de forma a garantirem o cumprimento cada vez mais exigente das prescrições e especificações técnicas dos manuais que regulam estas práticas.
Estas especificações e prescrições surgem em resposta à legislação que gere o setor das telecomunicações nomeadamente o Decreto-Lei no 123/2009 de 21 de Maio de 2009, com a redação dada pela Lei no 47/2013 de 10 de Julho de 2013.

Importa salientar que a 1a Edição do Manual ITED data de Julho de 2004, sendo a 2a Edição de Novembro de 2009 e a 3ạ Edição de Setembro de 2014. Com a 3ạ Edição, alguns aspetos foram alterados, sendo:

- Obrigatoriedade de cálculo dos valores de tilt, e respetiva inclusão desses valores no projeto;

- Diminuição dos valores máximos de tilt entre o RGCC/SMATV e as tomadas terminais;

- Instalação de 2 tipos de antenas, sendo uma antena para UHF, que assegure a captação de sinais nas zonas digitais $\mathrm{A}$ e antena parabólica que assegure a captação do sinal da TDT nas zonas digitais B;

- Introdução de valores máximos das atenuações das ligações permanentes para 862 e 2150 MHz;

Existem outras alterações no que diz respeito às prescrições mínimas das redes de cabos coaxiais para edifícios de diferentes tipos.

Outra grande alteração é o facto de esta Edição dar grande importância à nova realidade do setor imobiliário, em que a prioridade está não na construção de edifícios novos, mas sim na reabilitação de edifícios já existentes.

Desta forma, o manual indica o procedimento a ser utilizado para o dimensionamento de redes coaxiais nestes edifícios já construídos. 


\section{Aplicação Informática}

Para dar resposta ao mercado foi desenvolvida uma aplicação informática, de forma a apoiar os projetistas no dimensionamento de redes de cabos coaxiais em redes coletivas e individuais. Aquando deste desenvolvimento, as soluções existentes no mercado estavam limitadas no que toca aos equipamentos passíveis de ser utilizados. A implementação proposta possibilita o dimensionamento para 2 marcas distintas: a TEKA e TELEVES.

Pretendeu-se que a ferramenta fosse versátil e simples, do ponto de vista do utilizador, e que fosse também prática e intuitiva. Concomitantemente, esta ferramenta confere ao projetista um leque de opções para que este possa efetuar um correto e completo dimensionamento.

Esta aplicação foi desenvolvida em folha de Excel e recorrendo também ao suplemento VBA.

Basicamente, a aplicação informática desenvolvida efetua o cálculo das atenuações das ligações permanentes bem como os respetivos valores de tilt, quer para uma rede coletiva, quer para uma rede individual. Possibilita, ainda, a inserção de equipamentos ativos e passivos para a correção de valores de atenuação e de tilt. Por fim, e de forma automática, a ferramenta devolve o intervalo de valores em que devem estar compreendidos os níveis de sinal na $C R$ para MATV (Master Antenna Television) e SMATV (Satellite Master Antenna Television).

Esta ferramenta funciona de mesma forma, quer a rede seja constituída por 1 ou 2 fogos como para 50 ou mais fogos.

O ficheiro está portanto constituído por cinco folhas de cálculo:
1. Cálculos Rede Coletiva;
2. Cálculos da Rede Individual;
3. Rede Coletiva + Rede Individual;
4. Rede Individual;
5. Base de dados de equipamentos.

A aplicação informática efetua o cálculo das atenuações e tilt para a zona correspondente à rede coletiva de um edifício, permitindo a compensação do mesmo. O projetista deverá introduzir o número de saídas do secundário do RG-CC (no de fogos).

Seguidamente, apenas terá que escolher os equipamentos que achar mais adequados e introduzir os comprimentos das ligações permanentes.

O cálculo de atenuação é então efetuado de acordo com a fórmula constante da 3a Edição do Manual ITED:

\section{$A l p=A c a b o+A D R+n+A c+A T T$}

Sendo:

ALp atenuação da ligação permanente $(d B)$;

Acabo atenuação do cabo em função do comprimento (dB);

ADR atenuação dos dispositivos de repartição, ou derivação, se aplicável (dB);

N número de conetores considerados;

Ac atenuação por conetor $(\mathrm{dB})$;

ATT atenuação da tomada terminal, se aplicável (dB).

Após os valores de atenuações e de tilt estarem calculados, verificam-se se estes estão dentro dos limites exigidos. Caso não estejam o utilizador poderá compensar estes valores com equipamentos ativos e passivos que permitam precisamente a compensação destes. Para isso, terá que introduzir os valores da compensação na respetiva célula, conforme caso de estudo da próxima secção. Com o cálculo das atenuações e tilt, e no caso de não estarem dentro do limite, o programa retorna, também, um valor mínimo necessário para a respetiva compensação.

A aplicação permite também o "Cálculos da Rede Individual", sendo realizado o cálculo das atenuações e tilt para a parte da rede correspondente à rede individual. O utilizador deverá escolher o repartidor de cliente a ser usado. Terá, ainda, que escolher uma tomada terminal (TT) dentro de uma lista pendente composta por 2 equipamentos, um da marca TEKA e outro da marca TELEVES. 
Após o cálculo e se os valores estiverem fora dos limites, o programa dá sugestões para a respetiva compensação. São, ainda, assinaladas as tomadas + e - favoráveis de cada fração bem como da rede completa. Para tal, o programa soma as atenuações da rede coletiva com as atenuações das respetivas ligações permanentes da rede coletiva, e então encontra as referidas tomadas.

Na aplicação denominada "Rede Coletiva + Rede Individual", são calculados os valores correspondentes ao mínimo e máximo de sinal em que os níveis de sinal devem estar compreendidos na cabeça de rede (CR), para MATV e SMATV, tal como é indicado no Manual ITED 3a Edição.

Foi criada uma outra funcionalidade denominada: "Rede Individual", onde o utilizador poderá efetuar o dimensionamento de uma rede composta apenas pela parte individual. Desta forma deverá preencher uma célula com o $\mathrm{n}$ - de tomadas terminais da rede a dimensionar. Escolhendo, então, os equipamentos a utilizar os valores das atenuações e de tilt são automáticas calculados. Também aqui é indicado se os valores estão dentro dos limites, e caso não estejam, são dadas sugestões para a respetiva compensação.

Por fim a funcionalidade: "Base de dados de equipamentos", encontram-se os vários modelos de cabos, repartidores de cliente e tomadas terminais alusivos às duas marcas usadas. A aplicação informática foi desenvolvida em conformidade com os requisitos do Manual ITED 3a Edição.

\section{Aplicação Informática}

Afim de testar as capacidades e fiabilidade da aplicação, será apresentado de seguida um exemplo prático que segue os valores do exemplo prático do Manual ITED 3a Edição.

\section{Para o efeito foi considerada uma rede constituída por 4 frações com 8 tomadas cada.}

Seguindo o procedimento do ponto anterior, os valores resultantes do cálculo das atenuações da Rede Coletiva são os constantes na Figura 1.

Estes valores estão próximos dos valores do Manual, sendo que os respetivos desvios explicam-se com o facto de que os valores de atenuações de equipamentos que aqui foram utilizados são ligeiramente diferentes, tendo sido neste caso utilizados valores reais de equipamentos existentes no mercado.

No caso da rede individual foi considerado que as 4 frações têm a mesma tipologia, ou seja o mesmo comprimento para as ligações permanentes, entre o repartidor de cliente e das tomadas terminais. Assim, a Figura 2 apresenta os resultados referentes ao cálculo apenas para cada uma das frações.

Ainda na Figura 2 pode-se verificar que os resultados são aproximados aos valores do exemplo do Manual ITED.

Verifica-se que existem valores que estão fora dos valores limites, e que o programa dá sugestão do valor mínimo para a compensação destes. Neste caso, a seleção de um outro cabo com menores valores de atenuações corrigiu estes valores.

\begin{tabular}{|c|c|c|c|c|c|c|c|c|c|c|c|c|c|c|c|c|c|c|c|c|c|}
\hline 4 & A & c & D & E & $\mathrm{F}$ & G & H & 1 & J & K & $\mathrm{L}$ & M & N & 0 & P & Q & R & $s$ & T & U & v \\
\hline 1 & \multirow[t]{2}{*}{ Rede Coletiva } & \multicolumn{3}{|c|}{ Número de ATI } & 4 & & & & & & & & & & \multicolumn{2}{|r|}{ Preencher } & & & \multicolumn{2}{|l|}{ Apagar } & \\
\hline 2 & & & & \multicolumn{18}{|c|}{ ALp Col @ fMHz = Acabo@fMHz + nx AC@ fMHz } \\
\hline 4 & \multirow{3}{*}{ 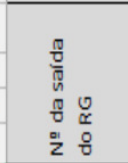 } & \multirow{3}{*}{ 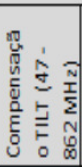 } & \multirow{3}{*}{ 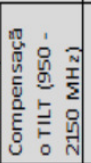 } & \multirow{3}{*}{ 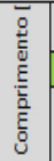 } & \multicolumn{4}{|c|}{ Acabo $[\mathrm{dB}]$} & $\overline{\bar{z}}$ & \multicolumn{4}{|c|}{$A c[d B]$} & \multicolumn{4}{|c|}{ Tilt [dB] } & \multicolumn{4}{|c|}{ ALp Col [dB] } \\
\hline$\frac{5}{6}$ & & & & & & \multicolumn{2}{|c|}{ TEKA RG6 N46V3 } & & 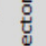 & & & & & $47 \cdot 86$ & & $950-215$ & & & & & \\
\hline 7 & & & & & 47 & 862 & 950 & 2150 & ह̊ & 47 & 862 & 950 & 2150 & Tilt (<-7) [dB] & Comp. & Tilt (<-9) [dB] & Comp. & 47 & $862(<18 \mathrm{~dB})$ & 950 & $2150(<26 \mathrm{~dB})$ \\
\hline 8 & RG-CC 1 & 0 & 0 & 15,0 & 0,63 & 2,87 & 3,02 & 4,65 & 2 & 0,01 & 0,17 & 0,19 & 0,43 & $-2,40$ & 0,00 & $-1,88$ & 0,00 & 0,64 & 3,04 & 3,21 & 5,08 \\
\hline 9 & RG-CC 2 & 0 & 0 & 30,0 & 1,26 & 5,73 & 6,03 & 9,30 & 2 & 0,01 & 0,17 & 0,19 & 0,43 & $-4,63$ & 0,00 & $-3,51$ & 0,00 & 1,27 & 5,90 & 6,22 & 9,73 \\
\hline 10 & $\mathrm{RG} \cdot \mathrm{CC} 3$ & 0 & 0 & 35,0 & 1,47 & 6,69 & 7,04 & 10,85 & 2 & 0,01 & 0,17 & 0,19 & 0,43 & $-5,38$ & 0,00 & $-4,06$ & 0,00 & 1,48 & 6,86 & 7,23 & 11,28 \\
\hline 11 & RG-CC 4 & 0 & 0 & 44,0 & 1,85 & 8,40 & 8,84 & 13,64 & 2 & 0,01 & 0,17 & 0,19 & 0,43 & $-6,72$ & 0,00 & $-5,04$ & 0,00 & 1,86 & 8,58 & 9,03 & 14,07 \\
\hline
\end{tabular}

Figura 1. Exemplo de cálculo da rede coletiva de CC 


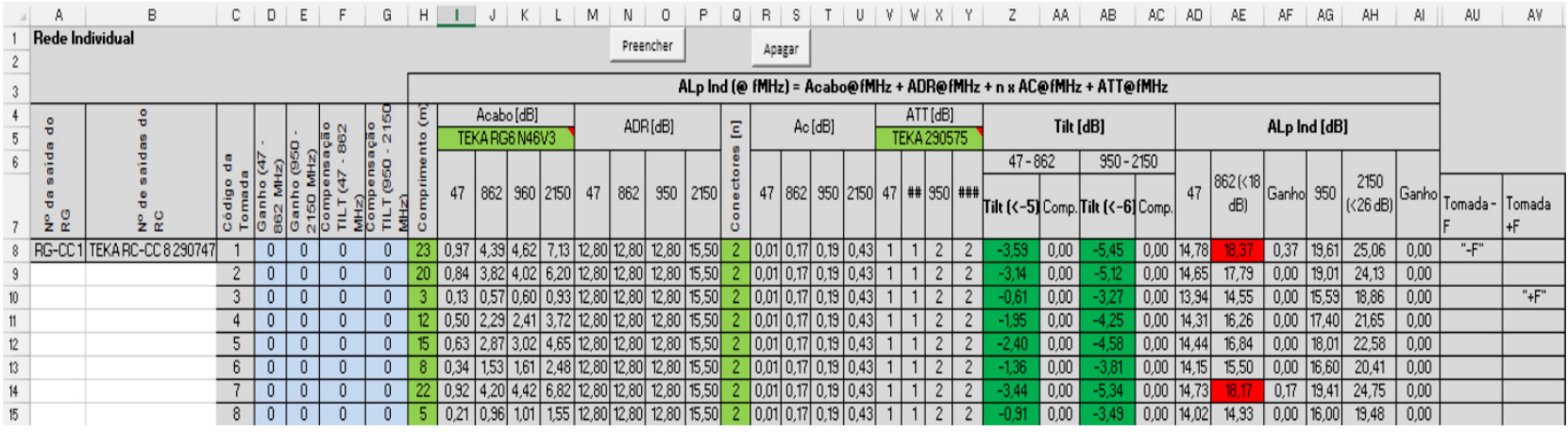

\section{Figura 2. Exemplo de cálculo da rede individual de CC}

Na Figura 3 encontram-se os valores em que devem estar compreendidos os níveis de sinal na CR para MATV e SMATV. Caso o utilizador queira dimensionar uma rede constituída apenas por parte individual, deverá utilizar a respetiva funcionalidade da aplicação para o efeito.
Para a escolha das marcas o critério de consideração foi a sua presença e posicionamento no mercado. Com efeito, estas duas marcas são, atualmente, na opinião dos autores, as marcas de referência no mercado das comunicações eletrónicas.

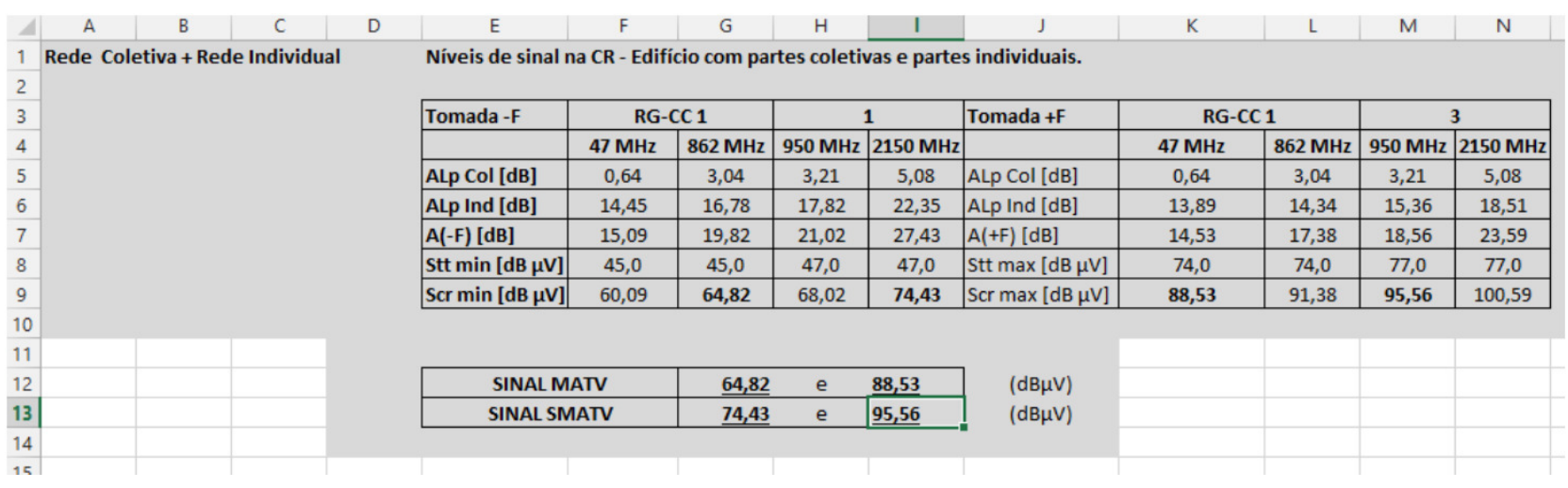

Figura 3. Níveis de Sinal na Cabeça de Rede (CR)

\section{Conclusões}

A aplicação informática implementada demonstra ser prática, simples e fiável, permitindo ao utilizador um correto dimensionamento de redes de cabos coaxiais, sendo uma mais-valia para os profissionais do setor, que agora dispõem de uma ferramenta que dá a possibilidade de escolha de equipamentos de, pelo menos, duas marcas (TEKA e
Não obstante o facto de que ainda assim estar algo limitada no que diz respeito à sua base de dados, futuramente existe a possibilidade de adicionar mais equipamentos, para que esta ferramenta se torne ainda mais completa e abrangente. TELEVES).

Este trabalho foi desenvolvido de acordo com o programa da Unidade Curricular de Projeto/Estágio de Sistemas Elétricos de Energia, da Licenciatura em Engenharia Eletrotécnica - Sistemas Elétricos de Energia. Sérgio Ramos e Marco Silva como orientadores e José Saavedra estudante do Instituto Superior de Engenharia do Porto - Instituto Politécnico do Porto (ISEP/IPP), Rua Dr. António Bernardino de Almeida, 431, 4200-072 Porto, Portugal (e-mail: 1110096@isep.ipp.pt).

O próximo trabalho foi desenvolvido de acordo com o programa da Unidade Curricular de Projeto/Estágio de Sistemas Elétricos de Energia, da Licenciatura em Engenharia Eletrotécnica - Sistemas Elétricos de Energia. Sérgio Ramos e Marco Silva como orientadores e Sérgio Vieira estudante do Instituto Superior de Engenharia do Porto - Instituto Politécnico do Porto (ISEP/IPP), Rua Dr. António Bernardino de Almeida, 431, 4200-072 Porto, Portugal (e-mail: 1110096@isep.ipp.pt). 